\title{
LOS CONFLICTOS DEL PASADO Y DEL PRESENTE EN EL MEDIO ORIENTE FACTORES QUE LOS ORIGINAN Y DERECHO NATURAL A OCUPAR LA
} TIERRA

\author{
Gabriela Aguado Romero y Luis Vázquez Martínez
}

\section{Resumen}

La guerra civil en Siria no es una conflagración aislada, pues está cronológicamente interconectada con todos los conflictos que se han suscitado en la región. Al hacer un recuento de los hechos nos percatamos de que hay algunas constantes relacionadas en las guerras originadas dentro de la región, sobre todo la lucha por el territorio, basada en la creencia con matices iusnaturalistas de un mayor derecho a ocupar la tierra, la intromisión permanente de Estados Unidos y Gran Bretaña, y la disputa por el control de los hidrocarburos. Estas problemáticas están rodeadas por el factor religioso, lo que ha provocado una lectura errónea del problema medular, pues se las considera como un asunto de fanatismo y se dejan de lado los factores de dominio territorial y económico.

Palabras clave: Medio Oriente, territorios ocupados, petróleo, conflictos bélicos, derecho natural.

\begin{abstract}
The conflicts in the past and in the present in the Middle East. Factors that originate it and the natural right to occupy the earth

The civil war in Syria is not an isolated conflagration, it is chronologically interconnected with all the conflicts that have arisen in the region. When you recount the facts there are some constants linked in the wars that have arisen in the region. Mainly the fight for the territory based on the belief with natural law nuances of a greater right to occupy the land, the permanent interference of the United States and Great Britain, and the dispute over the control of hydrocarbons. These problems are involved with the religious factor, which has led to an erroneous reading of the core problem, because this problem is considered a matter of fanaticism, leaving aside the factors of territorial and economic domain.
\end{abstract}

Keywords: Middle East, occupied territories, oil, wars, natural right.

Gabriela Aguado Romero: Doctora en Derecho por la Universidad Autónoma de Querétaro, México. Profesora e investigadora de la Facultad de Derecho e integrante del Cuerpo Académico Consolidado Derechos humanos y globalización de la misma facultad y universidad. Miembro del Sistema Nacional de Investigadores del Consejo Nacional de Ciencia y Tecnología.

ORCID iD: https://orcid.org/0000-0003-3733-6459

E-mail: aguadogabriela@hotmail.com

Luis Vázquez Martínez: Licenciado en Comunicación Social por la Universidad Autónoma Metropolitana, México. Maestro en Administración Pública Estatal y Municipal por la Universidad Autónoma de Querétaro. Estudiante de la Licenciatura en Derecho de la misma universidad.

ORCID iD: https://orcid.org/0000-0002-4602-533X

E-mail: luis.vazquez.martinez31@hotmail.com

Recibido: 6 de junio de 2018.

Aprobado: 6 de octubre de 2018. 


\section{Introducción}

Para los habitantes de los países occidentales, donde, si bien aún predomina la religión católica, existe una cierta pluralidad de cultos que ha forjado una filosofía en la que impera la libertad de conciencia y creencia, con, por supuesto, una alta influencia eurocentrista. Estas condiciones tienden a hacer predominar en las sociedades occidentales una postura que no termina de comprender y dimensionar el conflicto en el territorio sirio, que si bien involucra varias dimensiones convergentes en el fuego cruzado de los distintos grupos, tiene al ámbito religioso como desacuerdo más antiguo de los que conforman el meollo del asunto.

Un escenario tan complejo lleva a la necesidad de desentrañar paso a paso la relación que han tenido a lo largo de la historia los factores de índole religiosa y política, que podrían parecer directrices que se construyen paralelamente como dos riachuelos que desembocan en el mismo cuerpo de agua, pero que, sin embargo, conforman un gran río por el que circulan corrientes de aguas dulces y saladas, claramente diferenciables las unas de las otras, pero imposibles de separar para cambiar su cauce.

El presente estudio analiza el conflicto social que tiene lugar en Siria, organizado sobre la dinámica de la protesta por el mejor derecho a ocupar la tierra. En este sentido, concurren dos ámbitos cruciales para explicar el origen del conflicto. En primer lugar, aparece el derecho natural a la ocupación de un territorio, en este caso por mandatos sagrados y que ha convertido este lugar en un campo de batalla donde se enfrentan pueblos que, por una convicción ideológica arraigada (religión), consideran tener el mejor derecho al asentamiento permanente. En segundo lugar, se encuentra la significación de la intervención de otras naciones que ven oportunidad en el contexto de un conflicto específico, mediante la cual se enmascaran los Estados que han tomado parte ofreciendo su apoyo hacia cada uno de los pueblos combatientes, pero con atención a sus propios intereses, lo que ha dado lugar a factores económicos y políticos que históricamente han alimentado la guerra.

El trabajo está organizado en tres grandes apartados. El primero reflexiona en torno al espacio simbólico que define la consideración de que por derecho natural se ha de ocupar un territorio. El segundo relata los sucesos que dieron origen al conflicto en Medio Oriente. Y el tercero menciona otros sucesos ocurridos a partir de la Revolución Islámica que contribuyeron a sostener la tensión en la región. 
El conflicto bélico que se desarrolla actualmente en Siria obedece a una trama compleja vinculada con otras guerras ocurridas en Medio Oriente, que se encuentran, a su vez, relacionadas entre sí, lo cual nos demuestra que la problemática regional tiene un mismo comienzo: el conflicto árabe-israelí. De hecho, podemos considerar que se trata de una guerra perpetua con períodos de tregua en los cuales vuelve a emerger de manera impetuosa la violencia como respuesta al problema de fondo sin resolver, esto es, el rechazo a la existencia de Israel (Carta Nacional Palestina, 1968).

Los países musulmanes de Medio Oriente consideran a la política sionista como imperialista, ilegítima, invasora y apegada al apartheid, ${ }^{1}$ pues entienden que la creación de Israel violentó la autodeterminación del pueblo palestino, lo que contradice a la Carta de las Naciones Unidas.

Lo anterior se encuentra dispuesto en el artículo 22 de la Carta Nacional Palestina:

"El sionismo es un movimiento político orgánico asociado con el imperialismo internacional y antagónico a toda acción por la liberación y a los movimientos progresistas del mundo. Es racista y fanático en su naturaleza, agresivo, expansionista y colonialista en sus objetivos, y fascista en sus métodos. Israel es el instrumento del movimiento sionista y la base geográfica para el imperialismo mundial colocados estratégicamente en medio de la patria árabe para combatir las esperanzas de la nación árabe por la liberación, la unidad y el progreso. Israel es una fuente constante de amenaza con respecto a la paz en Medio Oriente y el mundo entero. Puesto que la liberación de Palestina destruirá la presencia sionista e imperialista y contribuirá al establecimiento de la paz en Medio Oriente, el pueblo palestino busca el apoyo de todas las fuerzas progresistas y pacíficas, e insta a todos, independientemente de sus afiliaciones y creencias, a ofrecer al pueblo palestino toda la ayuda y apoyo en su justa lucha por la liberación de su patria" (Consejo Nacional Palestino, 1968)

Para delimitar el conflicto de manera contemporánea, es preciso observarlo a través de dos momentos: el primero refiere a la distribución del territorio palestino y el segundo comprende la fundación de Israel.

En cuanto a la primera situación, nos remitimos al 29 de noviembre de 1947, fecha de aprobación de la Resolución 181 por la Asamblea General de la Organización de las Naciones Unidas (ONU), en la cual se recomendaba la partición de Palestina en dos Estados, uno judío y otro árabe (Naciones Unidas, 1947, p. 5).

1 Sistema de segregación racial vigente en Sudáfrica y Namibia hasta 1992. 
En dicha resolución se contemplaba un corpus separatum ${ }^{2}$ que estipulaba además, de manera puntual, la restricción de cierta zona, que incluiría a las ciudades santas de Jerusalén y Belén, que sería administrada en régimen internacional por el Consejo de Administración Fiduciaria de las Naciones Unidas. Es decir, ni árabes ni judíos podrían tener control sobre estas ciudades, aunque esto solamente ha resultado ser teoría, pues en la práctica el mandato lo ostentan los últimos.

Ya antes, la Asamblea General había preparado el terreno, pues el 15 de mayo de 1947 había creado el Comité Especial de las Naciones Unidas para Palestina (UNSCOP, por sus siglas en inglés), a petición de la delegación de Gran Bretaña, con la finalidad de formular recomendaciones según lo estipulado en el artículo 10 de la Carta de las Naciones Unidas, que dispone lo siguiente:

"La Asamblea General podrá discutir cualesquier asuntos o cuestiones dentro de los límites de esta Carta o que se refieran a los poderes y funciones de cualquiera de los órganos creados por esta Carta, y salvo lo dispuesto en el Artículo 12 podrá hacer recomendaciones sobre tales asuntos o cuestiones a los Miembros de las Naciones Unidas o al Consejo de Seguridad o a este y a aquellos" (Naciones Unidas, 1945).

La UNSCOP emitió su informe el 31 de agosto de 1947 y los once países integrantes de la comisión votaron por mayoría a favor de la creación de dos Estados separados, uno árabe y otro judío. ${ }^{3}$

Tabla 1. Votación del Plan de las Naciones Unidas para la partición de Palestina, 1947

\begin{tabular}{cccc}
\hline \multicolumn{5}{c}{ Votación } & & \\
\hline Número & $\begin{array}{c}\text { Creación de dos } \\
\text { Estados }\end{array}$ & $\begin{array}{c}\text { Creación de un } \\
\text { Estado }\end{array}$ & Abstención \\
\hline 1 & Canadá & India & Australia \\
\hline 2 & Checoslovaquia & Irán & - \\
\hline 3 & Guatemala & Yugoslavia & - \\
\hline 4 & Honduras & - & - \\
\hline 5 & Perú & - & - \\
\hline
\end{tabular}

2 El término en latín significa 'cuerpo separado' y es utilizado para describir la zona correspondiente a Jerusalén y sus alrededores, incluida la ciudad de Belén. Este acuerdo se encuentra dentro del Plan de las Naciones Unidas para la partición de Palestina (1947), cuyo objetivo era que la zona en cuestión se pusiera bajo un régimen internacional debido a su importancia religiosa.

3 Cabe aclarar que, para mantener neutralidad, ninguna de las potencias involucradas en los asuntos de la región formó parte de este comité. 


\begin{tabular}{cccc}
\hline \multicolumn{4}{c}{ Votación } \\
\hline Número & $\begin{array}{c}\text { Creación de dos } \\
\text { Estados }\end{array}$ & $\begin{array}{c}\text { Creación de un } \\
\text { Estado }\end{array}$ & Abstención \\
\hline 6 & Suecia & - & - \\
\hline 7 & Uruguay & - & - \\
\hline
\end{tabular}

Fuente: Elaboración propia con base en Naciones Unidas (1947).

En la Tabla 1 se ven los países que participaron en las recomendaciones sobre la aprobación o rechazo de la conformación del Estado de Israel o la creación de un Estado en el cual convivieran ambos pueblos. La tabla muestra que la mayoría de los países que conformaban la Comisión (63\%) votó por la división de Palestina en dos Estados, mientras que el 27,2\% lo hizo por la creación de un solo Estado.

Ninguna de las dos partes estuvo de acuerdo totalmente con esta decisión, sin embargo, los judíos tomaron el espacio designado para ellos y poco a poco ocuparon por la fuerza los territorios de Gaza y Cisjordania, para poder integrar los tres sectores geográficos dispersos que originalmente les habían proporcionado.

El tiempo ha transcurrido y las circunstancias jugaron a favor de los judíos, lo que se comprueba con los resultados. Tal pareciera que todo fue parte de una maniobra planificada, pues de esta manera, además de dominar y expandirse, también podrían impedir la creación del Estado Palestino (Flapan, 1987, pp. 8-9), que hasta el 29 de noviembre de 2012 fue reconocido como un Estado limitado. Esto se dio como producto de las presiones de la comunidad internacional en el seno de las Naciones Unidas (Naciones Unidas, 2012).

Con respecto al segundo momento, nos remitimos al 14 de mayo de 1948, fecha en la cual terminó el mandato británico en Palestina (Sociedad de Naciones, 1922) ${ }^{4}$ y se fundó el Estado de Israel. Al día siguiente, hubo una declaración de guerra por parte de Irak, Siria, Transjordania, Líbano y Egipto contra la recién creada nación. Fue así como, tras la fundación del Estado judío, comenzó el primero de varios conflictos armados, conocido como la guerra de 1948, del que Israel salió triunfante (Cifuentes, 2009, p. 18).

Todo esto tiene un trasfondo que no ha sido claramente vislumbrado por las naciones inmiscuidas y es, precisamente, el derecho natural a ocupar la tierra, ya que, aunque se ha buscado justificar con antecedentes histórico-religiosos el derecho a un determinado territorio, se observa una contraposición entre las afirmaciones de las Escrituras Hebreas y el Corán sobre quién fue el verdadero

4 Fue una administración territorial encomendada por la Sociedad de Naciones, antecesora de la Organización de las Naciones Unidas (ONU). 
hijo de la promesa de Abraham y, por tanto, en razón de la descendencia, quién tiene el derecho original y legitimo a ocupar el territorio.

Por su parte, el aspecto económico es un factor transcendental, pues no debemos olvidar la riqueza petrolera de Medio Oriente. Es verdad que estas pugnas tienen un origen milenario, pero nos quedamos con los dos momentos ya mencionados como parteaguas de estos conflictos: la Resolución 181 de la ONU y la fundación de Israel.

A partir del fin de la Segunda Guerra Mundial, las hostilidades entre ambos pueblos se agudizaron debido a las decisiones tomadas en el seno de la ONU. De hecho, la Liga Árabe advirtió que tomaría todas las medidas necesarias, incluyendo la intervención armada, para impedir la aplicación del Plan de Partición. ${ }^{5}$

Esta situación no es accidental. El precedente de la creación del Estado de Israel se encuentra en la Declaración Balfour, de 1917, en la que se manifestaron de manera pública las intenciones británicas de apoyar la creación de "un hogar nacional para el pueblo judío en la región de Palestina" (Balfour, 1917, p. 1). Este comunicado fue firmado por el entonces ministro británico de Relaciones Exteriores, Arthur James Balfour, y dirigido al barón Lionel Walter Rothschild, un líder de la comunidad judía en Gran Bretaña.

\section{Metodología}

El presente estudio es una investigación jurídico-social realizada con un enfoque cualitativo. Siguiendo a Sánchez (2001, p. 346), se aclara que lo social no alude únicamente a lo abordado por la sociología, sino que incluye también los objetos de otras disciplinas, como la economía y la política. El objetivo es aplicar el rigor metodológico de un estudio analítico para hacer ciencia social, con la expresión del compromiso y la empatía que los autores de este artículo tienen por interpretar las luchas sociales que constituyen trincheras y refugios de resistencia en Medio Oriente.

Se comenzó por utilizar una metodología de análisis teórico-crítico sobre el tema del derecho natural a ocupar la tierra. En cierto momento, y por convenir a una mejor percepción de la problemática, se pasó al uso de una metodología de carácter histórico-descriptivo, mediante el relacionamiento de hechos históricos que anteceden al actual conflicto sirio con los factores que se consideran determinantes y que contribuyen al conflicto objeto del estudio, para finalmente sintetizar consideraciones respecto a un fenómeno social.

5 Con esta declaración, la Liga Árabe contravenía lo estipulado en la Carta de las Naciones Unidas, concretamente en el capítulo I, artículo 2, punto 4 que a la letra dice: "Los Miembros de la Organización, en sus relaciones internacionales, se abstendrán de recurrir a la amenaza o al uso de la fuerza contra la integridad territorial o la independencia política de cualquier Estado, o en cualquier otra forma incompatible con los Propósitos de las Naciones Unidas". 


\section{Derecho natural a ocupar la tierra}

El histórico debate respecto a la importancia que se le da al derecho natural frente al derecho positivo podría asemejarse por analogía al milenario conflicto en Medio Oriente, pues es incuestionable que en nuestro caso de estudio el derecho positivo no ha logrado dar solución al problema. Tanto la legislación local como la internacional no han cumplido con su principal objetivo: preservar los beneficios de lo que se considera una vida civilizada.

De manera muy general, el derecho positivo hace referencia a las leyes civiles, mientras que el derecho natural supone unas leyes naturales o principios morales que están por encima de las leyes civiles. El conflicto bélico actual en Siria nos demuestra que el origen es un problema común, la lucha árabe-israelí, que contra toda civilidad se trata de una guerra prolongada con períodos de tregua, en los cuales vuelve a emerger una y otra vez el problema original: el rechazo a la existencia de Israel, nación que ocupa el territorio reclamado por Palestina.

Las instancias internacionales han realizado constantes intentos para regular estas pugnas, básicamente mediante la aplicación de diversas disposiciones positivas. Sin embargo, la regulación no se ha logrado, debido a que ambos Estados afirman tener el derecho natural a ocupar la tierra. Esta situación ha sido asociada a una cuestión religiosa, que ha sido exhibida por ciertos países para justificar su intervención con intenciones de control y poder sobre la zona.

Cabe resaltar que las hostilidades aumentaron ante la intervención de naciones occidentales con el fin de regular positivamente a dichos Estados. No es posible encontrar una única concepción respecto a la noción de derecho natural. Las diferentes corrientes jurídicas le han dado numerosas interpretaciones. Sin embargo, se observa que sí existe univocidad respecto a la corriente iusfilosófica, denominada iusnaturalismo.

Por otra parte, consideramos necesario señalar como clave la etapa del derecho natural cristiano, en la que un ser sobrenatural, Dios, aparece como la fuente de la que emana la ley natural y a partir de la cual los primeros preceptos instituidos por él se hacen evidentes en la razón del hombre. Así, el derecho natural tenía que ver con estar de acuerdo con el orden divino. Sin embargo, la cualidad de dicha razón variaba según dos cuestiones: la primera, según si el hombre era pagano o cristiano, y la segunda, por las atribuciones dadas a las distintas razas (Cayón, 2010).

Ante la demanda de ocupar un mismo territorio, se comenzó a transitar por un camino lleno de conflictos, mediados por dos razones fundamentales. Por un lado, los árabes consideraban a los judíos como invasores y como una nación artificial, que fungía como satélite de Occidente, primero a favor de Gran Bretaña y luego de los Estados Unidos. Y, por otro lado, los judíos consideraban tener un mejor derecho sobre el territorio, ya que tenían la 
creencia de poseer un derecho original y divino a ocupar la tierra. ${ }^{6}$ Este fue el comienzo de una serie de disputas entre judíos y árabes.

La hostilidad de ambos pueblos es milenaria, presente prácticamente desde los orígenes de los tiempos según el Antiguo Testamento (Génesis 25:19-28). Los judíos aparentemente son descendientes de Isaac y los árabes de Ismael, medio hermanos e hijos de Abraham. De acuerdo con las escrituras de ambos pueblos (Escrituras Hebreas y Corán), Isaac era hijo legítimo y su madre era Sara, no así Ismael, quien es vástago de una esclava egipcia de nombre Agar (Génesis 16:1-6), y desde siempre existieron rencillas entre ellos. Sin embargo, el conflicto principal fue por saber quién era el verdadero hijo de la promesa de Abraham: mientras las Escrituras Hebreas manifiestan que era Isaac, el Corán afirma que era Ismael (Corán 2:124-128).

La muerte de Mahoma - el máximo prócer del islam, considerado el mensajero de Dios - sin haber designado a un heredero propicia la separación de los partidarios del islamismo en chiitas, sunitas, jariyíes y alauitas. Las dos primeras son las principales corrientes del islam y las últimas dos subdivisiones que representan a minorías. Si bien sunitas y chiitas comparten la idea de que Alá es el único dios, Mahoma es su mensajero en la tierra y el Corán es la palabra de Dios, la discordancia proviene de que al morir Mahoma la facción chiita convino en el sucesor debía ser Alí, que era su primo paterno y yerno. De aquí que podamos traducir a la chía como 'los partidarios', como los que se autoproclaman 'partidarios de Alí'.

Por otro lado, tenemos a la sunna, que se traduce como 'tradición', es decir, la corriente ortodoxa del islam, que optó por seguir el sistema consultivo que había establecido el profeta para designar al sucesor y reconoció a Abu Bakr como el primer sucesor, a pesar de que solo ejerció como califa durante dos años y luego designó como sucesor a Umar ibn al Jattab. Esta evidente marginación de Alí creó descontento entre sus seguidores, lo que dio inició a la lucha ideológica existente desde hace más de catorce siglos (Aboud, 2016).

Si bien no es el objeto de este estudio realizar un análisis histórico de la evolución religiosa, quisimos marcar el inicio de esta problemática, sin dejar de reconocer que ha sido una constante hasta nuestros días.

Sin embargo, lo que ocurre actualmente en Medio Oriente dista mucho de ser un efecto lineal de la referida división del islam, puesto que en el territorio siempre han coexistido respetuosamente las diferentes ramas, con sus propias mezquitas para rendir culto, e incluso hay una minoría practicante del cristianismo. Un ejemplo de este respeto eran los distintos barrios en los que, por un lado, los islámicos cerraban sus negocios los viernes, porque es el día designado para acudir a rezar a los templos, y, por otro lado, los cristianos

6 Concepción judeocristiana que guarda comunión con las ideas iusnaturalistas de la etapa del derecho natural cristiano. 
hacían lo propio los domingos. Así, se podían ver cerrados los negocios de cada creyente según el día designado para su culto.

A pesar de que este asunto tiene un matiz religioso, a través del cual el derecho natural se proyecta como un derecho divino a ocupar la tierra (lo cual es relevante en Medio Oriente), también es preciso recordar que esta lucha se da en un territorio donde "originariamente nunca hubo algo parecido a la propiedad de la tierra, el hombre no creó la tierra, $y$, aunque tuviera el derecho natural a ocuparla, no tendría derecho alguno a ubicar su propiedad a perpetuidad en parte alguna" (Durán, 1997, p. 201).

Si efectivamente esto fuese regulado conforme al derecho natural, la tierra en estado natural debió y debería ser propiedad común de la raza humana, pues la condición de toda persona nacida en el mundo es la de ocupar un espacio de tierra, entendida como el suelo con todos sus productos. Esta es una conexión indiscutible, ya que la materia ocupa un espacio y el cuerpo del ser humano es materia, por lo que, con mayor razón, la condición de una sociedad políticamente organizada es la de ocupar un determinado territorio.

Como señala Durán:

"Es únicamente al reconducir las cosas a sus orígenes cuando podemos captar las ideas justas sobre ellas; y es precisamente el adquirir esas ideas lo que nos posibilita descubrir los límites de lo justo y de lo injusto, y lo que enseña a cada hombre a conocer su derecho" (Durán, 1997, p. 201)

Sería erróneo presuponer que el conflicto es predominantemente de índole religiosa, pues también debemos considerar los factores económicos y geopolíticos. Por lo tanto, es preciso abordar la temática como un problema geopolítico con tintes religiosos, de lo contrario se la estaría analizando con una mirada sesgada, que torna incomprensible la magnitud del conflicto y convierte toda aseveración proyectada en mera falacia, carente de sustento real y fáctico.

\section{Sucesos que dieron origen al conflicto}

Las luchas bélicas ocurridas a partir de la guerra de 1948 han sido más que constantes en Levante. A continuación, nombramos las más relevantes. En 1956, se generó la guerra del Sinaí, en la que se enfrentaron Egipto y la Liga Árabe contra Israel — con Gran Bretaña y Francia como aliados-, al perder este último su única salida al mar Rojo.

Lo que dio origen a las hostilidades fue la nacionalización del canal de Suez por parte de los egipcios. La construcción del canal había sido realizada por Francia y Egipto, pero este vendió a Gran Bretaña su participación. Sin embargo, luego del golpe de Estado que depuso en Egipto al rey Faruq I, el nuevo líder, el general Gamal Abdel, implantó una política de corte socialista que intentó nacionalizar el canal. Esto causó que los británicos tomaran la 
decisión, junto con los franceses y judíos, de bombardear objetivos militares egipcios para obligarlos a reabrir el canal de Suez. Para el restablecimiento de la paz fue necesaria la intervención de Estados Unidos y la entonces Unión de Repúblicas Socialistas Soviéticas (URSS).

Israel había obtenido el control del monte Sinaí, pero, por presiones de Estados Unidos y la Unión Soviética, se vio obligado a devolverlo a Egipto, que además recuperó el control del canal. No obstante, la alineación de Israel con los países occidentales debe ser entendida como el inicio de un proceso en pro de mayor y mejor armamento para esta nación.

En 1967, Israel atacó por sorpresa a Egipto, Siria y Jordania, en una operación veloz. El nuevo conflicto bélico es conocido como la guerra de los Seis Días. En esta lucha hubo alrededor de quince mil muertos y más de cincuenta mil heridos, lo que propició que la Organización para la Liberación de Palestina (OLP) ${ }^{7}$ se replanteara su razón de ser, su esencia misma, lo que a la postre derivó en que tomara un papel mucho más activo en el campo político.

Esta decisión significó para la OLP perder la simpatía de muchos palestinos, que ya no se sentían representados y optaron por engrosar las filas de movimientos como Fatah, en Kuwait, y el Movimiento Nacionalista Árabe (MNA), en Irak, cuya lucha contra Israel era mediante tácticas de guerra de guerrillas. Sin embargo, el nuevo líder de la OLP, un joven llamado Yasir Arafat, consideraba que los palestinos querían un movimiento que diera como resultado un Estado independiente.

En un inicio, la misión de este movimiento era la destrucción del Estado de Israel. De hecho, en sus estatutos, plasmados en su carta orgánica, pide abiertamente su aniquilación y el retorno de los palestinos desplazados por las distintas guerras (Hamid, 1975, pp. 90-109).

La Carta Nacional Palestina, en su artículo 8, expresa:

"La fase de la historia que está atravesando hoy el pueblo palestino es la de la lucha nacional por la liberación de Palestina. En consecuencia, los conflictos entre las fuerzas nacionales palestinas son secundarios y deben ser finalizados en bien del conflicto básico que existe entre las fuerzas del sionismo y del imperialismo, por una parte, y del pueblo árabe palestino, por la otra. Sobre esta base, las masas palestinas, sin consideración de si están residiendo en la patria nacional o en la diáspora, constituyen - tanto sus organizaciones como sus individuos - un frente nacional que trabaja por la recuperación de Palestina y su liberación a través de la lucha armada" (Consejo Nacional Palestino, 1968$)^{8}$

7 Mientras que para Israel esta organización es un grupo terrorista, para los árabes es un organismo compuesto por grupos rebeldes que buscan la independencia de Palestina.

8 Traducción propia. 
En 1968 surgió una nueva conflagración conocida como la guerra de desgaste, que tuvo como característica primordial la violencia discrecional, pues prevalecieron las escaramuzas y enfrentamientos de baja intensidad con tácticas y estrategias propias de la guerrilla. De hecho, este conflicto es visto como una continuación de la guerra de los Seis Días. Egipto pretendía recobrar el Sinaí, sin embargo, tras la firma de los tratados de paz en 1970, las fronteras quedaron igual que cuando empezó la guerra.

En octubre de 1973, Egipto y Siria se unieron y nuevamente pretendían apoderarse del Sinaí y de los Altos del Golán, respectivamente, para lo cual le declararon la guerra al enemigo en común, Israel. Este enfrentamiento fue denominado como guerra del Yom Kipur. ${ }^{9}$ En un primer momento, el factor sorpresa jugó a favor de los árabes en los dos frentes, sin embargo, poco a poco, Israel recuperó las posiciones perdidas.

Esta pugna duró solamente del 6 al 25 de octubre de 1973, pero sus repercusiones fueron prolongadas, porque posibilitaron que los países del golfo Pérsico miembros de la Organización de Países Productores de Petróleo (OPEP) boicotearan, el 16 de octubre de ese año, la venta de crudo a los países occidentales que apoyaron a Israel (Blinder, 1979). Esto provocó que la inflación aumentara y derivó en una crisis económica a escala mundial.

Precisamente en este período, marcado por una elevada inflación y una economía estancada, se acuñó el término estanflación. La estanflación es el momento económico en el que se produce un estancamiento de la economía y el ritmo de la inflación no cede. Esta definición combina los términos recesión e inflación y refiere a uno de los peores escenarios económicos que se puede presentar, debido a la dificultad para su manejo y corrección. El término había sido utilizado por primera vez en 1965 por el entonces ministro de Finanzas de Gran Bretaña, Ian McLeod, en un discurso ante el Parlamento:

"Ahora tenemos lo peor de ambos mundos: no solo inflación por un lado y estancamiento por el otro, sino ambos juntos. Tenemos una especie de 'estanflación'. Y, en términos modernos, se está haciendo historia" (McLeod, $1965)^{10}$

Después de sostener cinco guerras contra de Israel, el 17 de septiembre de 1978 Egipto aceptó firmar la paz, lo cual fue visto como una traición a la causa palestina, incluso Arafat llegó a señalar que era una puñalada por la espalda y aunque firmaran una infinidad de papeles, eso no significaba nada, puesto que esa no era una amistad natural.

El proceso de firma de la paz entre los líderes de Egipto, Anwar al Sadat, e Israel, Menjájem Beguín, bajo el auspicio del entonces presidente de los

\footnotetext{
9 Yom Kipur es la conmemoración judía del Día de la Expiación, en el que prevalecen el perdón y el arrepentimiento.

10 Traducción propia.
} 
Estados Unidos, James Carter, es conocido como los acuerdos de Camp David y derivó en que varios países árabes rompieron relaciones diplomáticas con Egipto y en el asesinato del presidente Al Sadat en 1981.

Pero regresemos por un momento al año 1970. Ese año el rey Huseín de Jordania expulsó a los miembros de la OLP, que hasta entonces vivían en su país en campos de refugiados, pues ya las contiendas entre estos y las Fuerzas Armadas Reales de Jordania eran numerosas y desestabilizaban a la nación. Los palestinos huyeron al Líbano, donde intentaron reorganizarse.

En julio de 1980, el parlamento israelí, conocido como Knéset, aprobó la Ley Fundamental: Jerusalén, Capital de Israel (Sefer Ha-Jukim, 1980, p. 186), mediante la cual declaraba: "Jerusalén completa y unida es la capital de Israel". Esta legislación generó una fuerte respuesta mundial. El Consejo de Seguridad de la ONU acordó no reconoce la controvertida ley ni otras acciones que buscasen alterar el carácter y estatus de Jerusalén (Steinsleger, 2017, p. 31 ), hecho que a la postre suscitó un nuevo conflicto.

Entre 1982 y 1983 se desató la guerra del Líbano, en la que Israel combatió contra el Líbano y Siria. Israel llevó a cabo la operación militar Paz para Galilea, con la cual los sionistas tenían como objetivo limitar la capacidad de acción de los palestinos, efecto que consiguieron tomando el control de la frontera libanesa. La economía libanesa quedó destrozada.

\section{La revolución islámica, un movimiento contraproducente para Israel y Occidente}

Es menester señalar que las pugnas mencionadas no son los únicos conflictos ocurridos en la región, ya que se han dado otra serie de sucesos en los cuales Israel no ha participado, al menos de forma directa, pero que han beneficiado a este país, tales como golpes de Estado producidos en naciones árabes o agresiones realizadas por países occidentales, principalmente Estados Unidos y Gran Bretaña.

No obstante, debemos empezar por mencionar un hecho histórico poco conveniente para Israel y que ha cambiado por completo la geopolítica regional. Este hecho es la Revolución Islámica de Irán de 1979. Este movimiento fue un golpe duro para las pretensiones sionistas, en tanto modificó radicalmente el tablero regional, puesto que la República Islámica de Irán pasó a orientarse hacia la independencia y no hacia el alineamiento con Occidente.

Con el ascenso al poder del movimiento encabezado por el ayatolá Jomeini, Estados Unidos no solamente perdió un aliado en la región, sino que ganó un enemigo, puesto que la dinastía Pahlaví — que gobernaba hasta entonces en Irán - sí reconocía al Estado de Israel, pero la nueva república islámica se declaró enemiga tanto de Israel como de Estados Unidos. 
Irán cuenta con un programa nuclear desde la década de los cincuenta, con un desarrollo bastante avanzado, que continúa hoy en día, sin el apoyo de asistencia técnica de Occidente. En un principio esto no representaba un problema para Estados Unidos, pero a partir de 1979, con el ascenso del ayatolá Jomeini, pasó a ser un asunto de cuidado.

Sin embargo, el país persa insistió en que su desarrollo de la energía nuclear es con fines pacíficos y tiene como prioridad la generación de combustible doméstico. Estados Unidos e Israel aseguraron, en cambio, que el programa tiene como finalidad el desarrollo de armas nucleares para llevar a cabo un posible ataque contra la nación israelí, fundamentados en la existencia de alrededor de dieciséis plantas nucleares dispersas por todo el país musulmán (Yazd Radiation Processing Center, 2006).

Si bien es cierto que Israel logró llegar a acuerdos de paz con Egipto, esta súbita revolución islámica en Irán dejó claro que había pasado a tener otro enemigo poderoso. Al ser Irán una potencia emergente en la región, contaba con los elementos para que su posicionamiento súbito e inesperado influyese sobre los países próximos. Rudolf Kjellén introdujo la idea de que un Estado tiene que crecer y desarrollarse o simplemente morir (Kjellén, 1916). Irán lo entendió y creció a ritmo acelerado en la cuestión armamentista.

En cuanto al presente, la llamada guerra civil en Siria no es el resultado fortuito de una rebelión de grupos subversivos, sino que más bien obedece a un plan perfectamente diseñado, en el que nuevamente se responsabiliza a Estados Unidos e Israel de querer desestabilizar a la región (ahora concretamente a Siria) a través de grupos extranjeros mercenarios. Se afirma que hay organizaciones terroristas financiadas con este propósito, entre ellas el Estado Islámico.

El pasado reciente nos demuestra que tal afirmación no es una mera casualidad, simplemente basta con ver los últimos conflictos que se han presentado: las dos guerras contra Irak con la finalidad de derrocar y ejecutar a Sadam Huseín, la represión que ejerce Israel sobre Palestina, de la que ya es un emblema el muro de la ignominia que se levantó en esa región, y el reconocimiento por parte de Estados Unidos de Jerusalén como capital de Israel.

Estos sucesos solamente han contribuido a la tensión regional en Levante. Además, se han presentado otros movimientos financiados desde Occidente. Concretamente, nos referimos a la Primavera Árabe, que se caracterizó por la aparición repentina de varias revueltas civiles que provocaron un efecto dominó y llevaron consigo el derrocamiento de los regímenes dominantes en distintos países, pero también inestabilidad y carencia económica.

La Primavera Árabe tuvo su inicio en Túnez, a raíz de la inmolación de un vendedor ambulante que se vio despojado de sus mercancías, una forma extrema de protesta contra un régimen despótico. Este hecho aconteció el 17 de diciembre de 2010 y fue el inicio de varias manifestaciones contra mandatarios 
musulmanes en distintos países de la región. Las protestas fueron de todo tipo, unas menores (lo cual no significa que hayan sido poco intensas, sino más bien que fueron desactivadas a tiempo $)^{11} \mathrm{y}$ otras más cruentas, derivadas en guerras civiles que depusieron a presidentes. Tal es el caso de Egipto, Libia, Túnez y Yemen.

Siria es otra nación que sufrió los embates de una revolución, iniciada hace siete años con protestas pacíficas en las calles de su capital, Damasco. Sin embargo, podemos decir que los movimientos subversivos que se presentaron de manera repentina obedecieron al control que Estados Unidos e Israel quieren ejercer en la región.

Es verdad que en el interior de cada una de estas naciones no impera la democracia, negarlo sería una necedad, pero eso a Occidente solo le importa cuando se trata de buscar un pretexto para intervenir en alguna nación que es considerada un peligro para el orden mundial dominante o que simplemente no se alinea a los intereses económicos hegemónicos, sobre todo cuando se trata de petróleo. Occidente actúa de acuerdo con el beneficio o perjuicio que cada régimen de Medio Oriente le puede proporcionar y de allí surge el apoyo que brinda o la desestabilización que provoca.

Existen dos países que están muy pendientes de lo que sucede en Siria: Rusia e Irán. El primero porque tiene dos bases militares en territorio sirio, una naval en el puerto de Tartús y otra aérea en Hmeimim. Israel ha sido acusado de haber atacado a la primera de ellas, lo cual pone más tensión al asunto, pues tuvo como consecuencia el envío de asesoría y armamento militar ruso al gobierno de Bashar al Ásad. Por su parte, Irán decidió tomar una participación mucho más activa en el conflicto, mediante la movilización de sus tropas hacia territorio sirio con la finalidad de generar una cortina protectora de su territorio y así repeler lo que ellos consideran como un avance sionista hacia su propia nación. Israel, mientras tanto, asegura haber sufrido ataques desde Siria por parte de la nación persa.

Por todo lo anterior, podemos afirmar que el objetivo final de esta guerra no es Siria, sino más bien Irán, pues los movimientos militares de Israel se encaminan a cercar las posibles salidas de este último. Irán ha reaccionado para evitar estar rodeado de países con gobiernos proestadounidenses, lo que resultaría catastrófico para el régimen de los ayatolás, ya que si Estados Unidos e Israel tuviesen el control territorial y gobiernos afines a ellos, podrían intentar deponer al régimen islámico.

Por otro lado, nuestra tesis se fortalece al ver cómo Washington rompió el pacto que tenía con Irán desde 2015, conocido como acuerdo nuclear y cuyo nombre oficial es Plan de Acción Integral Conjunto (PAIC). El gobierno de Donald Trump rompió así otro de los compromisos suscrito por su antecesor,

11 El caso más representativo es el de Arabia Saudita, nación que tiene un régimen tiránico, pero, sin embargo, nunca reprobado por Washington, ya que Riad colabora con Estados Unidos. 
Barack Obama. Además, Trump restableció las sanciones económicas contra Irán, lo cual también afecta a sus aliados europeos y es también por este motivo que las relaciones se han vuelto más tensas en la región, pues se ven afectados los países firmantes del acuerdo: China, Francia, Gran Bretaña, Alemania y Rusia (Naciones Unidas, 2015).

No se vislumbra una solución a corto plazo, pero es apremiante que Estados Unidos no dé marcha atrás y, por lo tanto, no abandone este pacto, para que se pueda al menos tener una paz exigua en la región. Pero tal parece que Washington continuará privilegiando la fuerza sobre la negociación para lograr imponer su agenda económica y política.

Esto ha quedado demostrado con la decisión de Estados Unidos de cambiar la sede de su embajada de Tel Aviv a Jerusalén y la aceptación de esta como capital de Israel, que fue una muestra de soberbia y una actitud retadora al mundo. Es verdad que Israel tiene derecho a existir, sin embargo, esto no debe ser a cualquier costo, lo que implica que sus vecinos árabes también tienen derecho a vivir en paz.

\section{Reflexiones finales}

Las distintas guerras que se han desarrollado en Medio Oriente tienen un común denominador: el no reconocimiento del Estado de Israel por parte de las naciones árabes. El conflicto tiene su punto medular en la región de Palestina, pues aquí es donde se determinó que debía fundarse esta nación, lo que significó el desplazamiento del pueblo palestino.

La disputa por el territorio entre árabes y judíos se caracteriza por el reclamo que hacen estos últimos de una tierra que aseguran les pertenece por decreto divino, pues de acuerdo con sus tradiciones, la tierra donde están asentados es la tierra prometida por Dios al patriarca Abraham y su descendencia. Sin embargo, los árabes afirman que ese pacto estuvo hecho entre Dios, Abraham y el verdadero primogénito de este último, Ismael, quien es de descendencia árabe.

Sería erróneo presuponer que el conflicto es predominantemente de índole religiosa y a esto agregarle los factores económicos y geopolíticos. Por lo tanto, es preciso abordar la temática como un problema geopolítico con tintes religiosos, de lo contrario, se la estaría analizando con una mirada sesgada, que torna incomprensible la magnitud del conflicto y convierte toda aseveración proyectada en mera falacia, carente de sustento real y fáctico.

Actualmente, la situación en Siria no es un pleito aislado, sino todo lo contrario, se trata de un conflicto interconectado con la problemática árabe-israelí, lo que nos deja entrever que es un eslabón más de esta guerra prolongada, que presenta períodos de tregua, pero en la que después de un 
tiempo la violencia vuelve a recrudecer de manera impetuosa. Israel y sus aliados (Estados Unidos, Gran Bretaña y Francia) pretenden hacerse del dominio territorial de la región.

Como lo hemos señalado en este estudio, también existe una riqueza petrolera que se pretende administrar. Sin embargo, para poder conseguirlo, primero hay que tener la región bajo control económico y militar. Este dominio, también estratégico, ha sido logrado por Israel y sus aliados de manera paulatina pero constante. Sin embargo, Siria no es el objetivo final de esta nueva incursión militar, es solamente una parada más, pues el verdadero objetivo es derrocar al gobierno de la República Islámica de Irán.

La misión es compleja, porque Irán tiene como aliados a Rusia y China, lo que traba aún más la situación que impera en la región. La tensión ha llegado a un grado tal que incluso es posible considerar que se desate una guerra de dimensiones internacionales, lo que hace necesario que no se escatimen esfuerzos para encontrar una salida pacífica a un conflicto en el que una y otra vez emerge de manera impetuosa la pugna original: el rechazo a la existencia de Israel.

Cuando replanteamos las cosas desde sus orígenes es cuando podemos discernir las situaciones justas de las injustas, y esto es lo que permite a cada hombre conocer su derecho y defenderlo justamente. Conforme a las leyes del derecho natural, defendemos el derecho de quienes fueron despojados de su herencia natural y desposeídos de su tierra, al igual que defendemos el derecho del que posee la parte que es suya.

Los factores político-económicos externos han creado un velo que impide resolver el conflicto, pues agregan un ingrediente que entorpece la solución del problema de origen. Este podría solucionarse aplicando las leyes del derecho natural, pero el contexto internacional derivado de la lucha por el control y el poder sobre el territorio de Medio Oriente ha imposibilitado este resultado. 


\section{Referencias bibliográficas}

Aboud, S. (2016). Herederos de Mahoma: chiíes contra sunníes, un conflicto milenario. El Mundo [en línea], 7 de enero. Disponible en: $<\mathrm{https} / / / \mathrm{www}$. elmundo.es/la-aventura-de-la-historia/2014/06/23/53a7fab9ca4741cc30 8b4581.html> [acceso 12/05/2018].

Balfour, A. (1917). Declaración Balfour [carta] (comunicación personal de Arthur Balfour a Lionel Rothschild, 2 de noviembre de 1917).

Blinder, A. (1979). Economic Policy and the Great Stagflation. Nueva York: Academic Press.

Cayón, L. (2010). Descubriendo la naturaleza. Derecho natural y ordenamiento territorial indígena en la Amazonia colombiana. Anuário Antropológico, I(2010), pp.199-226.

Cifuentes, O. (2009). La historia de Israel y Palestina. Tomo I. Santiago de Chile: Ercilla.

Consejo Nacional Palestino (1968). Carta Nacional Palestina.

Flapan, S. (1987). The birth of Israel: Myths and realities. Nueva York: Pantheon Books.

Hamid, R. (1975). What is the PLO? Journal of Palestine Studies, 4(4), pp. 90-109.

Kjellén, R. (1916). El Estado como forma de vida. Estocolmo: Hugo Gebers Publishing.

Ley Fundamental: Jerusalén, Capital de Israel (1980). Sefer Ha-Jukim, 980 (5 de agosto), p. 186.

Liga de las Naciones (1922). Mandato británico para Palestina, (resolución del 24 de julio).

McLeod, I. N. (1965). House of Commons' Official Report. Vol. 720, col. 1165, (17 de noviembre).

Naciones Unidas, Asamblea General (1945). Carta de las Naciones Unidas (1945). Disponible en: <https://www.un.org/es/charter-united-nations/> [acceso 12/05/2018].

Naciones Unidas, Asamblea General (1947). Resolución aprobada sobre la base del informe de la comisión ad hoc encargada de estudiar la cuestión de Palestina A/RES/181(II) (29 de noviembre). Disponible en: <http://www. un.org/es/comun/docs/?symbol=A/RES/181(II)> [acceso 12/05/2018]. 
Naciones Unidas, Asamblea General (2012). Estatuto de Palestina en las Naciones Unidas, A/RES/67/19 (4 de diciembre). Disponible en: <https://undocs.org/ es/A/RES/67/19> [acceso 12/05/2018].

Naciones Unidas, Consejo de Seguridad (2015). Plan de Acción Integral Conjunto, S/2015/544 (14 de julio). Disponible en: <https://undocs.org/es/S/2015/544> [acceso 12/05/2018].

Sánchez, R. (2001). Metodología de la ciencia del derecho. México: Porrúa.

Steinsleger, J. (2017). Israel no es un Estado judío, ni Jerusalén su capital eterna. La Jornada, 13 de diciembre.

Yazd Radiation Processing Center (YRPC) (2006). Nuclear Threat Initiative [en línea]. Disponible en: <https://www.nti.org/> [acceso 12/05/2018].

\section{Contribución de autoría}

Los autores contribuyeron en partes iguales a la redacción del artículo. 